\title{
Chronic Wound Healing: A Review of Current Management and Treatments
}

\author{
George Han (D) - Roger Ceilley
}

Received: October 20, 2016 / Published online: January 21, 2017

(c) The Author(s) 2017. This article is published with open access at Springerlink.com

\begin{abstract}
Wound healing is a complex, highly regulated process that is critical in maintaining the barrier function of skin. With numerous disease processes, the cascade of events involved in wound healing can be affected, resulting in chronic, non-healing wounds that subject the patient to significant discomfort and distress while draining the medical system of an enormous amount of resources. The healing of a superficial wound requires many factors to work in concert, and wound dressings and treatments have evolved considerably to address possible barriers to wound healing, ranging from infection to hypoxia. Even optimally, wound tissue never reaches its pre-injured strength and multiple aberrant healing states can result in chronic non-healing wounds. This article will review wound healing physiology and discuss current approaches for treating a wound.
\end{abstract}

Enhanced content To view enhanced content for this article go to http://www.medengine.com/Redeem/ A287F06016A19FA2.

G. Han $(\square)$

Icahn School of Medicine at Mount Sinai, New York, NY, USA

e-mail: george.han@mountsinai.org

R. Ceilley

University of Iowa, Iowa City, IA, USA
Keywords: Biofilms; Chronic wounds; Growth factors; Hyperbaric oxygen; Negative pressure wound therapy; Skin infection; Skin substitutes; Wound dressings; Wound healing

\section{INTRODUCTION}

The process of cutaneous wound healing is incredibly complex, dependent on an intricate interplay between a number of highly regulated factors working in concert to restore injured skin towards repaired barrier function. This sequence of events plays out normally in the vast majority of superficial wounds; however, it can go awry at numerous steps along the pathway, especially with underlying disease states such as diabetes. When wound healing does not progress normally, a chronic wound may result and this is at significant burden to both the patient and the medical system. It has been estimated that a single diabetic ulcer carries a cost of nearly US\$50,000 [1] and chronic wounds as a whole cost the medical system over US $\$ 25$ billion per year, with the number of patients affected growing yearly from 6.5 million, given the increasing prevalence of diabetes and other chronic diseases that may affect wound healing [2]. Aside from the burden of a chronic wound, even simple wounds created after minor procedures such as outpatient surgeries require 
proper attention and care, and understandably, patients may be concerned about possible resultant scarring. It is no surprise, then, that wound healing has received a great deal of attention, both from a basic science standpoint and a business perspective. The basic science of how a wound heals is fascinating, with new discoveries elucidating mechanisms of physiologic wound repair constantly being reported. Meanwhile, wound healing is also a huge commercial enterprise, with the market for wound care products exceeding US\$15 billion and treating wound scarring another US $\$ 12$ billion [3]. In this review, basic concepts of wound healing will be discussed, with a focus on current practice in treatment of wounds and future directions in wound care. This article is based on previously conducted studies and does not involve any new studies of human or animal subjects performed by any of the authors.

\section{PHYSIOLOGIC WOUND HEALING}

After a superficial wound, a myriad of systems are activated at the site in order to clear foreign material, as the primary barrier function of the skin is lost, and to eventually restore the normal structure of the skin. While this may only be successful to a limited degree-a wound will never reach the maximum tensile strength of unwounded skin, and at best reaches about 70\% [4] - most of the essential functions of the skin will be returned to a wound. This does, however, require the delivery of various inflammatory cells, chemokines, cytokines, matrix molecules, and nutrients to the wound site with a concordant increase in metabolic demand. These processes occur simultaneously and are generally divided into three main phases of wound healing: inflammatory, proliferative, and remodeling.

The inflammatory phase of wound healing starts shortly after hemostasis is achieved, and the primary goal of this phase is to clear pathogens as well as foreign material from the wound and to contain the damage to a localized area. Vascular permeability increases with vasodilation, allowing neutrophils and monocytes to localize to the wound site. A complex interplay of cytokines also helps to regulate this phase, culminating in monocyte conversion to macrophages, often thought of as the master regulator of this inflammatory phase of wound healing [5]. The macrophages not only phagocytose and digest tissue debris and remaining neutrophils but also secrete growth factors and cytokines that promote tissue proliferation and cell migration. After about 3 days from the initial wound, the proliferative phase centers around fibroblasts and production of both collagen and ground substance that will form the basis for the tissue scaffold of the previous wound area. Meanwhile, endothelial cells enter a rapid growth phase and angiogenesis occurs within the granulation tissue, creating a rich vascular network supplying this very active area of healing. After about 2-3 weeks, the wound transitions to a remodeling, or maturation, phase where the collagen type is restored to usual (type I, rather than type III seen in a new wound) [6] and the wound tissue matures, resulting in full cross-linking and restoration of a somewhat normal structure. The vascular network rapidly regresses as well [7]. As previously discussed, the wound strength never reaches its normal, pre-injury state.

An important consideration in physiologic wound healing is oxygen supply and oxygen tension in the wound bed. Wound healing requires oxygen to interact with numerous cytokines, supply the actively proliferating cells, as well as provide an effector for the neutrophil respiratory burst. It has been estimated that a wound requires at least a tissue oxygen tension of $20 \mathrm{mmHg}$ to heal [8] and non-healing wounds have been measured to have oxygen tensions as low as $5 \mathrm{mmHg}$ [9]. These effects seem to compound one anotherin situations of low oxygen tension, not only will there be more necrotic debris to facilitate bacterial growth but the primary mechanism of the immune system in combating these microbes is compromised. Thus, special care must be taken with wounds resulting from peripheral vascular disease and also in cases where vascular compromise may play a role, such as a diabetic ulcer. Additionally, the 
systemic optimization of nutritional status should be evaluated in wound healing. Numerous nutrients have proven to be important in wound healing, especially protein intake [10]. This was illustrated in a study of elderly patients with pressure ulcers where change in ulcer area was significantly correlated with protein intake [11]; however, other factors are also important, such as vitamins $A$ and $C$, and zinc [12]. The fine balance of these nutrients has to be taken into account, though. For example, with vitamin $\mathrm{E}$, an important lipophilic antioxidant, conflicting studies have both shown reduced tensile strength and collagen content of experimental wounds [13, 14] and, conversely, increased wound strength and collagen [15]. As with all aspects of wound repair, a fine balance is necessary to ultimately achieve proper healing.

Given the tight regulation of a multitude of factors required for proper wound healing, it is not surprising that chronic wounds are rather common. After an acute wound such as trauma, surgery, or even a bug bite, the above well-coordinated series of events come into play. The ultimate time course and outcome will depend on the nature of the acute woundits location, size, depth, and type. However, when other pathologic factors come into play, such as an underlying disease state, a chronic wound can form (see Fig. 1). This refers to a wound that has somehow deviated from the previously described natural physiologic course of events and has stalled at some point. The underlying mechanism varies greatly, but includes factors influencing blood supply (peripheral vascular disease), immune function (such as immunosuppression or acquired immunodeficiency), metabolic diseases (such as diabetes), medications, or previous local tissue injury (such as radiation therapy). External factors, such as sustained pressure, temperature, and moisture, also play an important role in allowing a wound to heal. As the pathophysiology of normal acute wound healing has been well described, this review will mainly focus on chronic wounds and their treatment.

Aberrant wound healing can be seen rarely in normal healthy subjects, but is usually

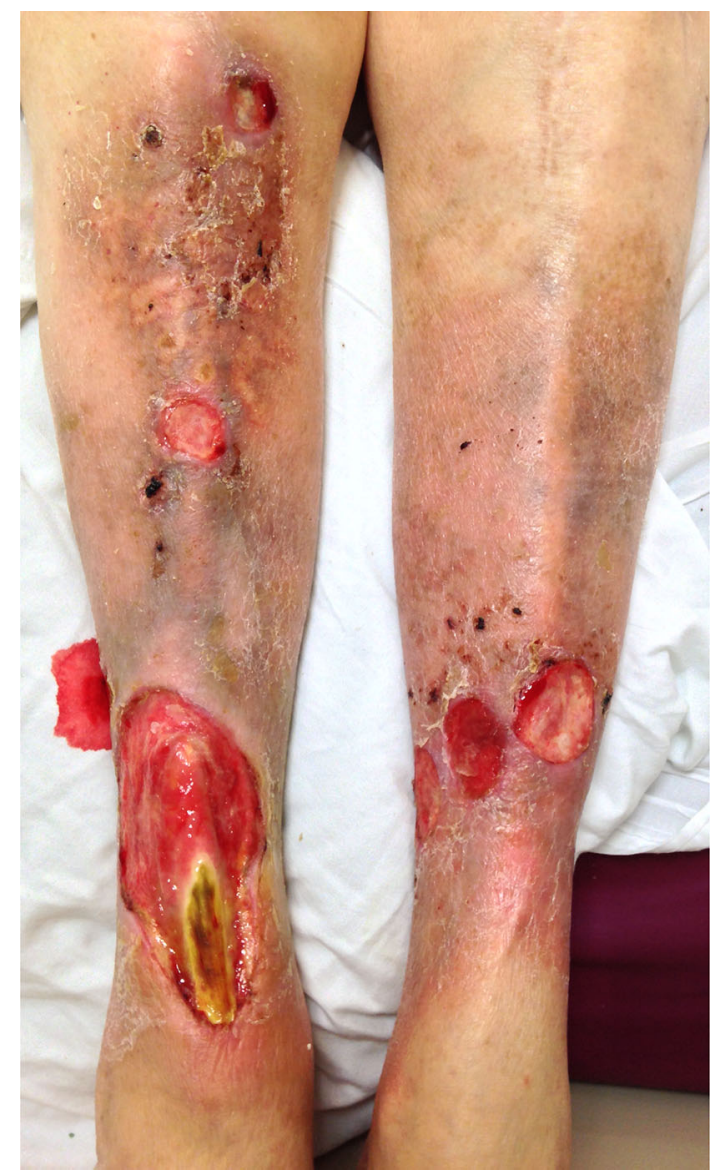

Fig. 1 Chronic ulcers of peripheral vascular disease

associated with an underlying process, ranging from diabetes to cancer to malnutrition. Of the major concerns for chronic wounds, perhaps none is as menacing or as important as diabetes. In the USA, the number of people with diabetes already reaches 20 million and is expected to double by the year 2030 [16]. Diabetic foot ulcers affect $15 \%$ of these patients and precede the vast majority of amputations in this patient population [17]. A wide variety of factors is thought to contribute to this problem, affecting all phases of wound healing and seemingly nearly every molecule involved in this process [18], and evidence is emerging that proper glycemic control can have a significant impact on the rate of wound healing in a diabetic patient [19]. This effect was mainly seen in patients with markedly elevated hemoglobin A1c levels, but it underscores emerging evidence that diabetes plays a 
multifactorial role in wound healing. It has been well described that the neuropathy experienced by diabetics can lead to a loss of protective sensation, producing wounds that eventuate into ulcers; however, there is an emerging role of advanced glycation end products in contributing to not only this neuropathy but also the wound healing cascade and small vessel disease [20]. While achieving good glycemic control can certainly be challenging, it also serves to reinforce the need to address lifestyle choices and integration of the primary care provider into treating a chronic wound.

\section{WOUND INFECTIONS}

The most common preventable challenge to wound healing is possible infection, and topical antimicrobials have long been used empirically to attempt to prevent wound infection. While bacteria are a normal part of the skin flora and thus wounds, a critical threshold of $10^{5}$ bacteria has been proposed as the delineation between colonization and a clinically relevant infection that may impede wound healing [21]. It is also necessary to distinguish between an incidental positive culture and a true pathogen affecting a wound. Repeat surface cultures in a wound are of limited use, neither confirming nor ruling out a continued infection; rather, clinical diagnosis of an infected wound remains of primary importance [22]. Deep tissue cultures are somewhat more controversial. While they have better sensitivity and specificity in isolating a causative organism in an infected wound, it is still not perfect; isolates from different parts of the same wound have even been shown to have different organisms [23]. Additionally, the practitioner is, in essence, exacerbating the initial wound with an even deeper wound, but this may still be a worthwhile trade-off if it guarantees appropriate antimicrobial coverage.

There are many approaches towards both treatment and prevention of wound infections. Silver has been used as adjunct in wound care for over 2000 years [24] and remains a popular wound care ingredient today. It has a broad spectrum of activity and is available in numerous forms. Newer advances in using silver for wound healing have focused on allowing for sustained release of silver in high enough concentrations to allow for retained efficacy. Nanocrystalline silver dressings were developed with this in mind and help to address the shortcoming that silver nitrate has-to work properly, it would have to be administered 12 times a day [25]. Furthermore, a recent review found no convincing evidence that silver sulfadiazine has any effect on wound healing overall, despite its common use among practitioners [26]. Similarly, iodine-containing compounds have long been used in wound healing but there have been some concerns with toxicity of iodine-containing compounds, especially over large wound areas. For limited wounds, though, cadexomer iodine (iodine within a starch lattice formed into microbeads) has a good deal of data supporting its use as a cost-effective adjuvant for wound healing $[27,28]$.

Numerous topical formulations of antibiotics have also been developed to apply to wound sites. They remain popular, even though emerging evidence has shown that the benefit of this wholesale application of antibiotic ointments may not be necessary and the only real indication for topical antibiotics is a clinically infected wound, such as purulent drainage, erythema, warmth, pain, tenderness, or induration [29]. Numerous recent studies have echoed this sentiment, with routine administration of antibiotic ointment leading to no better outcomes but often resulting in patient discomfort, along with the possibility of antibiotic resistance and contact dermatitis $[30,31]$. This is in conflict with a few earlier studies where children with minor scratches and insect bites had reduced rates of infection with topical antibiotic ointment [32, 33], although this cannot be clearly generalized to all patients. Even after Mohs micrographic surgery, a prospective study found the rate of infection after clean surgical technique to be less than $1 \%$, with the highest rate of infections in flap closures [34]. Overall, the consensus seems to be that in dermatology, use of topical antibiotics should be reserved for conditions 
such as impetigo or a clearly infected wound and not for general prophylaxis [35].

\section{WOUND CARE AND DRESSINGS}

Wound care has become increasingly important given the rise of chronic wounds and the morbidity associated with them. An important concept in wound care is the role of debridement, or the removal of non-viable tissue material. This can be achieved through surgical or autolytic/enzymatic mechanisms-in either case, the goal is to expose healthy, well-perfused tissue that is able to proliferate and populate the wound bed via epithelial cell migration, rather than keeping necrotic debris which only serves as fuel for infection and impedes wound healing. The optimal timing and frequency of surgical debridement are still unclear, as they are likely to vary greatly depending on the type of wound being treated, but there is general agreement that surgical debridement is an important component of wound care. Autolytic debridement refers to the self-activation of endogenous enzymes involved in fibrin degradation generated in a moist wound environment and seen with some types of wound dressings [36]. While this can have some utility in wound healing, it is certainly not capable of removing devitalized tissue as well as surgical debridement and, as such, cannot serve as adequate replacement for surgical debridement. Recently, there has been some renewed interest in the use of so-called biosurgical debridement, or the application of larvae/maggots to a wound. This is intriguing in that it achieves both a mechanical/surgical debridement and an enzymatic debridement at the same time, whilst having the capability to eliminate pathogenic organisms and stimulate fibroblast proliferation [37, 38]. Further studies are needed, but it is certainly an intriguing concept.

Many wound dressings have been developed to try to both protect the healing wound from infection and also to help promote the wound healing process itself (Table 1). A moist occlusive dressing helps support the inflammatory phase by creating an environment with low oxygen tension (thereby activating such factors as hypoxia-inducible factor-1) [39] and also increases the rate of re-epithelialization [40]. Additionally, a limited amount of exudate retained on the wound allows for autolytic debridement, which serves to further promote successful wound healing. However, traditional dry gauze wound dressings may degrade this process while also causing further injury when removed. Low adherent dressings and semipermeable films (i.e., Tegaderm) represent the basic types of wound dressings commonly in use, with the goal of restricting liquid and microbial penetration but allowing air and water vapor through. Hydrocolloids and hydrogels take advantage of a hydrophilic material that absorbs a certain amount of exudate but keep a moist environment; hydrocolloids are furthermore impermeable to air and are somewhat more long-lasting, but should not be used on exudative wounds because of its impermeable nature. Hydrogels may additionally be used to help promote moisture in an otherwise dry wound. Another option is alginate dressings, seaweed-derived non-woven fibers that are generally reserved for highly exudative wounds because of their ability to absorb large amounts of fluid. As such, adverse effects can be seen in dry wounds dressed with alginate [41]. Similarly, foams have some absorptive capacity and can be used on moderately exudative wounds, especially helpful because they minimize trauma during dressing changes. Lastly, collagen products have been used on recalcitrant wounds and chronic ulcers. While this collagen is not intended to be a direct replacement for new production of collagen in wounded tissue (as it can be derived from multiple sources, including bovine and porcine collagen), it is thought to help facilitate an environment attracting cell types critical to wound healing while depleting negative effectors such as free radicals and proteases [42].

Several more recent developments in wound dressings have focused on integrating antimicrobial compounds into the wound dressing itself. These materials combine traditional wound dressings such as foams or hydrogels with antimicrobial compounds such as silver, betaine, chitin, or polyhexamethylene biguanide (Kendall AMD). These materials, as 
Table 1 Currently available wound dressings

\begin{tabular}{|c|c|c|}
\hline $\begin{array}{l}\text { Type of } \\
\text { dressing }\end{array}$ & Commercially available products & Notes \\
\hline Gauze & Curity, Vaseline Gauze, Xeroform & $\begin{array}{l}\text { Inexpensive, drying, may cause further } \\
\text { injury on changing }\end{array}$ \\
\hline Films & Bioclusive, Blisterfilm, Cutifilm, Flexigrid, OpSite, Tegaderm & $\begin{array}{l}\text { Occlusive, retains moisture, only for } \\
\text { non-exudative wounds }\end{array}$ \\
\hline Hydrocolloids & Aquacel, Comfeel, DuoDERM, Granuflex, Tegasorb & $\begin{array}{l}\text { Long times between changes, } \\
\text { fluid-trapping, occlusive, not for } \\
\text { infected wounds }\end{array}$ \\
\hline Hydrogels & Carrasyn, Curagel, Nu-Gel, Purilon, Restore, SAF-gel, XCell & $\begin{array}{l}\text { Rehydrates dry wounds, easy removal/ } \\
\text { changes, may cause over-hydration }\end{array}$ \\
\hline Foams & 3M Adhesive Foam, Allevyn, Lyofoam, Tielle & Moderately absorbent, insulating \\
\hline Alginates & Algisite, Kaltostat, Sorbsan, Tegagen & Highly absorbent, hemostatic \\
\hline Hydrofibers & Aquacel Hydrofiber & Highly absorbent \\
\hline $\begin{array}{l}\text { Tissue } \\
\text { engineered } \\
\text { skin } \\
\text { substitutes }\end{array}$ & $\begin{array}{l}\text { Alloderm, Apligraf, Biobrane, Bioseed, Dermagraft, Epicel, } \\
\text { EZ Derm, Hyalograft, Integra Omnigraft, Laserskin, } \\
\text { Myskin, TransCyte }\end{array}$ & $\begin{array}{l}\text { Addresses deficient growth factors and } \\
\text { cytokines, expensive, risk of infection, } \\
\text { antigenicity }\end{array}$ \\
\hline
\end{tabular}

discussed previously, may not be appropriate for broad-spectrum application to healing wounds, but may be appropriate in chronic lower leg ulcers where infection can be a problem, especially with formation of biofilms. Many pathogens are able to adhere together into biofilms, which represent tightly packed masses surrounding a polymeric matrix, thus helping to evade destruction by antibiotics. This creates not only a physical barrier to wound healing but one in which the normal resolution of the inflammatory phase may be prolonged, and addressing biofilms has become a major challenge in wound healing. Both in vitro tests and patient data show that these antimicrobial wound dressings can be helpful in chronic pressure/venous ulcers that may be affected by these biofilms $[43,44]$.

\section{SKIN SUBSTITUTES}

While skin substitutes have long been used in grafts (mostly from autologous sources) either for significant surgical defects or burns necessitating replacement of a large surface area of tissue, advances in this field have allowed for the development of novel bioprosthetic skin substitutes. These materials generally consist of a biologically derived substance combined with a material to allow for its placement on a wound. Overall, these dressings are quite costly, representing a significant barrier to widespread adoption. However, several studies have been conducted to look at cost-effectiveness and many of these have shown an advantage with using these expensive substitutes, considering that reducing even a single day of a hospital admission represents an enormous cost saving, not to mention being much better for the patient. While multiple options have focused on a mesh material coated with porcine collagen or polypeptides (Biobrane and Transcyte, the latter of which also contains newborn fibroblast cells) or a porcine xenograft (EZ Derm), it is not clear whether they represent a cost-effective option for general application, 
although one study suggested that it was associated with decreased cost of care and improved outcome in a relatively limited scope of facial burns [45]. Perhaps more interesting, however, is a material developed using fibroblasts derived from newborn foreskin tissue, extracellular matrix, and a bioabsorbable polyglactin mesh (Dermagraft). The fibroblasts in this material are able to generate growth factors, collagen, cytokines, and glycosaminoglycans to help support the wound healing environment. Numerous studies have borne out its efficacy [46, 47], especially for burn wounds and venous/pressure ulcers, but a few downsides are a theoretical risk of rejection (although unreported thus far) and hypersensitivity (as bovine serum may be contained in trace amounts in the preparation). This concept was taken one step further with Apligraf, an allogenic bilayered cultured skin equivalent, where a dermal layer of cultured fibroblasts and bovine type I collagen is combined with an epidermal layer of cultured keratinocytes, generating a material that can be absorbed much like a graft and generates a similar environment to a normally healing wound. While no dermal appendages or blood vessels are contained, it was shown that this material actually significantly increased blood flow by over $70 \%$ to the base of diabetic foot ulcers [48]. This comes at a significant cost, however, as a single application of Apligraf can cost over US\$1000 for a 7.5-cm-diameter circular disk. Again, as previously noted, this cost has been analyzed, taking into account shortened time to wound closure, and actually resulted in a cost savings over 1 year in wounds that fail to respond to traditional wound care [49]. However, this must be taken with the caveat that the study population consisted of recalcitrant, chronic, non-healing wounds, somewhat limiting the applicability in general of these products.

Another option which received a new FDA indication in 2016 for diabetic foot ulcers is the Integra Dermal Regeneration Template (Omnigraft). This material is an acellular bilayer matrix consisting of collagen, glycosaminoglycan, and chondroitin-6-sulfate, with a layer of silicone for barrier function [50].
It had been used since 1996 for burn wounds with a later approval for scars from burns, but more recently gained the approval for diabetic foot ulcers on the basis of a pivotal study from 32 sites and over 300 patients. The data showed that treatment with Omnigraft increased wound closure rate by $50 \%$ compared to standard of care, with time to wound closure reduced by 5 weeks. A major benefit of Omnigraft is that in the vast majority of cases $(72 \%)$, only one application of the substrate is needed for complete wound healing, with over $90 \%$ of wounds requiring two or less applications [50].

\section{NEGATIVE PRESSURE WOUND THERAPY}

Negative pressure wound therapy, or vacuum-assisted closure, has received a good deal of attention since first being used in the USA in 1997. By maintaining a moist environment, optimizing blood flow, removing exudates, and applying pressure to promote wound closure, these devices are able to mitigate numerous factors that may be deficient in a chronic wound. Additionally, numerous studies have shown that these devices are associated with reduced rates of infection in these wounds [51]. Meanwhile, dressing changes may be simplified and significant cost savings can be associated with a reduced need for surgical debridement over the long term. As a rule, these devices consist of a foam dressing (that requires changes, up to every other day) and an evacuation tube. Details of the exact material and irrigation fluids that can be run through the system concurrently have been developed, but in general, these devices range from simple portable home units to more complex machines designed for acute care settings such as burn units. One interesting emerging indication for negative pressure wound therapy is its use on a complicated surgical wound. As a temporizing measure, negative pressure wound therapy may reduce the volume of the wound, thereby simplifying the subsequent surgical repair of the wound [52]. 


\section{GROWTH FACTORS}

Growth factors in wound healing have received significant attention in the field of wound healing in the past few decades. However, the only one of these therapies proven to improve healing in a double-blinded randomized controlled trial is platelet-derived growth factor (PDGF) and those results were rather modest [53]. Nonetheless, it stands to reason that since a chronic wound contains so many perturbations in growth factors and cytokines, addressing some of these issues may be helpful. For example, a chronic wound tends to show decreased levels of epidermal growth factor (EGF), fibroblast growth factor (FGF), transforming growth factor- $\beta$ (TGF$\beta)$, PDGF, and vascular endothelial growth factor (VEGF) while expressing lower levels of interleukins (IL) 1 and 6, and tumor necrosis factor- $\alpha$ (TNF- $\alpha$ ) [54]. Perhaps most of this is due to the fact that in an environment where so many factors are deficient and dysregulated, simply replacing one is unable to rescue the chronic wound phenotype; alternatively, it is also likely that the "master regulator" of wound healing has yet to be addressed. In any case, the scientific literature is rife with reports of applying a certain growth factor, cytokine, protein, or hormone and achieving remarkable results in various models for wound healing, including all of the aforementioned growth factors and additional targets of interest $[55,56]$. Nonetheless, broad acceptance of these factors has remained lukewarm at best, perhaps limited in large by the cost of these factors. The data is also often difficult to interpret, as different models of wound healing are used and practical issues often limit the ability to control the study. It is worth noting that several insurance companies have begun to accept at least some forms of therapy, such as Regranex (becaplermin gel-a PDGF). A review of United Healthcare and Blue Cross Blue Shield policies reveals that at least some of these providers will reimburse for these growth factors given certain conditions (usually diabetic neuropathic ulcers being treated with adjunctive wound care). Work in this field is certainly still progressing, regardless of seemingly promising therapies such as TGF- $\beta$ supplementation notably failing to produce results such as shown with PDGF [57].

\section{HYPERBARIC OXYGEN}

Hyperbaric oxygen has been used in wound healing on the basis of the principle that it can promote fibroblast proliferation, enhance immune function, and stimulate angiogenesis, among other functions. However, these ideals have not necessarily borne out in practice, leading to some degree of controversy in its use. Importantly, this therapy is applied to the patient in a hyperbaric oxygen chamber as localized delivery of oxygen has not been shown to be effective (Fig. 2), which could lead to significant side effects including myopia, oxygen toxicity in the brain leading to seizures, and pneumothorax [58]. A Cochrane review was only able to show a modest increase in the likelihood of diabetic foot ulcers healing at 1 year, and even this was based on mostly smaller studies with questionable study design [59]. At this point in time, it seems that hyperbaric oxygen can only be considered in wounds where an ischemic diabetic ulcer has demonstrated hypoxia [60] and, even then, some of the newer approaches described previously may be of more benefit. This was in some ways underlined in a recent randomized controlled trial where hyperbaric oxygen as an adjunct did help wound healing but even the authors qualified their findings to be applicable only to "selected patients with diabetes" [61]. As that study was not powered to look at outcomes such as amputation, a clinical trial is currently underway to answer some of these questions by comparing standard wound care with or without hyperbaric oxygen therapy to prevent amputations in non-healing ulcers in diabetic patients [62].

\section{FUTURE DIRECTIONS}

With the economic and patient care impacts of wound healing, it comes as no surprise that the field of wound healing research is incredibly 


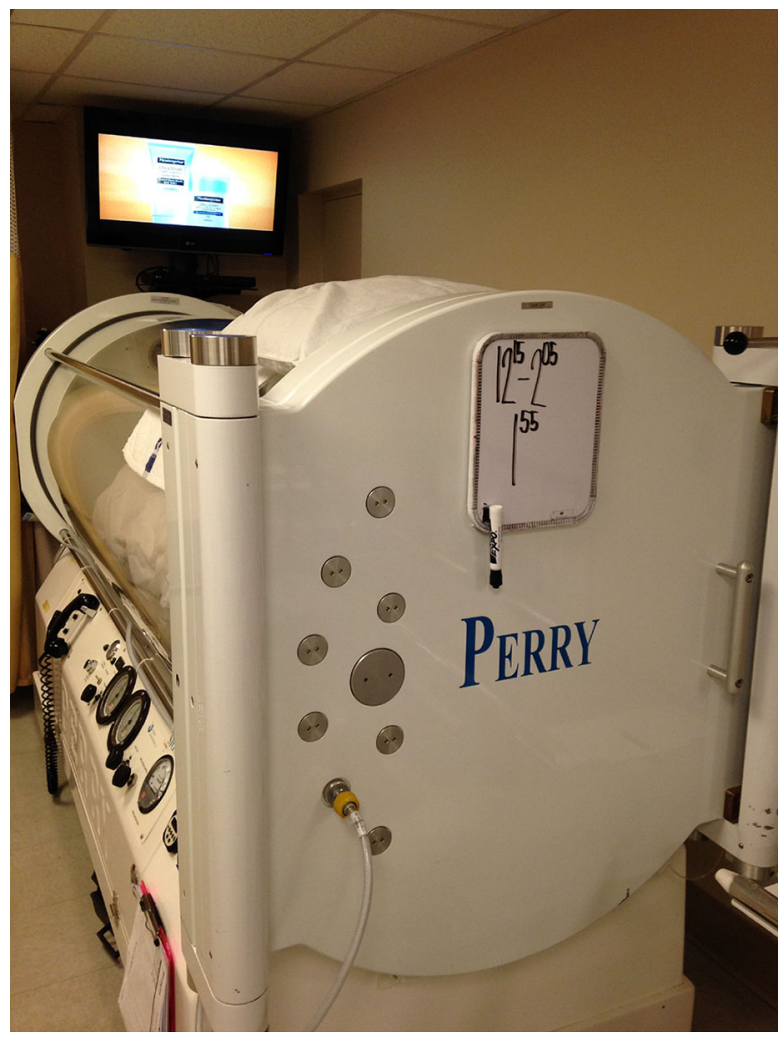

Fig. 2 Hyperbaric oxygen wound therapy chamber (Sigma 34 Hyperbaric Chamber, Perry Biomedical, Riviera Beach, FL, USA)

active. New research in wound healing comes from seemingly disparate fields ranging from materials science to molecular biology. Some of these have focused on novel molecules of interest in wound healing, such as nitric oxide, with numerous approaches to this end involving innovative material design $[63,64]$. While these approaches may be seen as helpful in wound healing and furthermore may, in essence, bypass some of the limitations of single growth factors or cytokines (especially as more broadly acting, gregarious molecules involved in the wound healing cascade are identified), it still will not approach the "holy grail" of wound healing.

It has long been appreciated that fetal wounds do not scar but understanding how this occurs has been much more difficult [65]. While this is something of a separate issue in terms of wound healing with much of the previous discussion focusing on chronic, non-healing wounds, the idea that a simple wound can heal without scarring or minimal scarring has been enticing nonetheless. In the fetus, a wound heals by regeneration rather than orderly repair [66]. Perhaps this correlates with the relatively pathogen-free environment seen in utero, and explains why the wound healing "switch" turns on sometime during late pregnancy, in the last trimester [67]. This has a corollary in the animal kingdom with reptilian limb regeneration and the more recently reported African spiny mouse (Acomys) [68]. Some researchers have sought to isolate individual factors that are up- or downregulated in the fetal wound, such as TGF, matrix metalloproteinases [69], and the such, but perhaps the greatest promise lies in stem cell therapy. Parallel to numerous successful research efforts in chronic wounds focusing on injecting stem cells from bone marrow into non-healing wounds [70, 71], more recent studies have also focused on using stem cells as scar-attenuating adjuncts to wound healing, leading to tissue regeneration rather than repair with subsequent formation of fibrotic scar tissue [72]. Until these therapies bear fruit, however, it may be best to practice the old adage, "protect your skin," and avoid the burden of a wound in the first place.

\section{ACKNOWLEDGEMENTS}

No funding or sponsorship was received for this study or publication of this article. All named authors meet the International Committee of Medical Journal Editors (ICMJE) criteria for authorship for this manuscript, take responsibility for the integrity of the work as a whole, and have given final approval for the version to be published.

Disclosures.. George Han and Roger Ceilley have nothing to disclose.

Compliance with Ethics Guidelines.. This article is based on previously conducted studies and does not involve any new studies of human or animal subjects performed by any of the authors. 
Data Availability.. Data sharing is not applicable to this article as no datasets were generated or analyzed during the current study.

Open Access. This article is distributed under the terms of the Creative Commons Attribution-NonCommercial 4.0 International License (http://creativecommons.org/licenses/ by-nc/4.0/), which permits any noncommercial use, distribution, and reproduction in any medium, provided you give appropriate credit to the original author(s) and the source, provide a link to the Creative Commons license, and indicate if changes were made.

\section{REFERENCES}

1. Paquette D, Falanga V. Leg ulcers. Clin Geriatr Med. 2002;18(1):77-88 (vi).

2. Brem H, Stojadinovic O, Diegelmann RF, et al. Molecular markers in patients with chronic wounds to guide surgical debridement. Mol Med. 2007;13(1-2):30-9.

3. Sen CK, Gordillo GM, Roy S, et al. Human skin wounds: a major and snowballing threat to public health and the economy. Wound Repair Regen. 2009;17(6):763-71.

4. Stadelmann WK, Digenis AG, Tobin GR. Physiology and healing dynamics of chronic cutaneous wounds. Am J Surg. 1998;176(2A Suppl):26S-38S.

5. Wynn TA, Barron L. Macrophages: master regulators of inflammation and fibrosis. Semin Liver Dis. 2010;30(3):245-57.

6. Haukipuro K, Melkko J, Risteli L, Kairaluoma M, Risteli J. Synthesis of type I collagen in healing wounds in humans. Ann Surg. 1991;213(1):75-80.

7. Gurtner GC, Werner S, Barrandon Y, Longaker MT. Wound repair and regeneration. Nature. 2008;453(7193):314-21.

8. Hunt TK, Hopf HW. Wound healing and wound infection. What surgeons and anesthesiologists can do. Surg Clin North Am. 1997;77(3):587-606.

9. Sheffield PJ. Tissue oxygen measurements. In: Hunt TK, Davis JC, editors. Problem wounds: the role of oxygen. New York: Elsevier; 1988. p. 17-52.

10. Ruberg RL. Role of nutrition in wound healing. Surg Clin North Am. 1984;64(4):705-14.
11. Breslow RA, Hallfrisch J, Guy DG, Crawley B, Goldberg AP. The importance of dietary protein in healing pressure ulcers. J Am Geriatr Soc. 1993;41(4):357-62.

12. MacKay D, Miller AL. Nutritional support for wound healing. Altern Med Rev. 2003;8(4):359-77.

13. Ehrlich HP, Tarver H, Hunt TK. Inhibitory effects of vitamin $\mathrm{E}$ on collagen synthesis and wound repair. Ann Surg. 1972;175(2):235-40.

14. Greenwald DP, Sharzer LA, Padawer J, Levenson SM, Seifter E. Zone II flexor tendon repair: effects of vitamins A, E, beta-carotene. J Surg Res. 1990;49(1):98-102.

15. Galeano M, Torre V, Deodato B, et al. Raxofelast, a hydrophilic vitamin E-like antioxidant, stimulates wound healing in genetically diabetic mice. Surgery. 2001;129(4):467-77.

16. Wild S, Roglic G, Green A, Sicree R, King H. Global prevalence of diabetes: estimates for the year 2000 and projections for 2030. Diabetes Care. 2004;27(5):1047-53.

17. Reiber GE, Vileikyte L, Boyko EJ, et al. Causal pathways for incident lower-extremity ulcers in patients with diabetes from two settings. Diabetes Care. 1999;22(1):157-62.

18. Brem H, Tomic-Canic M. Cellular and molecular basis of wound healing in diabetes. J Clin Invest. 2007;117(5):1219-22.

19. Christman AL, Selvin E, Margolis DJ, Lazarus GS, Garza LA. Hemoglobin A1c predicts healing rate in diabetic wounds. J Invest Dermatol. 2011;131(10):2121-7.

20. Peppa M, Stavroulakis P, Raptis SA. Advanced glycoxidation products and impaired diabetic wound healing. Wound Repair Regen. 2009;17(4):461-72.

21. Trengove NJ, Stacey MC, McGechie DF, Mata S. Qualitative bacteriology and leg ulcer healing. J Wound Care. 1996;5(6):277-80.

22. Armstrong DG, Liswood PJ, Todd WF. William J. Stickel Bronze Award. Prevalence of mixed infections in the diabetic pedal wound. A retrospective review of 112 infections. J Am Podiatr Med Assoc. 1995;85(10):533-7.

23. Schneider M, Vildozola CW, Brooks S. Quantitative assessment of bacterial invasion of chronic ulcers. Statistical analysis. Am J Surg. 1983;145(2):260-2.

24. Murphy PS, Evans GR. Advances in wound healing: a review of current wound healing products. Plast Surg Int. 2012;2012:190436. 
25. Warriner R, Burrell R. Infection and the chronic wound: a focus on silver. Adv Skin Wound Care. 2005;18(Suppl 1):2-12.

26. Miller AC, Rashid RM, Falzon L, Elamin EM, Zehtabchi S. Silver sulfadiazine for the treatment of partial-thickness burns and venous stasis ulcers. J Am Acad Dermatol. 2012;66(5):e159-65.

27. Skog E, Arnesjo B, Troeng T, Gjores JE, Bergljung L, Gundersen J, et al. A randomized trial comparing cadexomer iodine and standard treatment in the out-patient management of chronic venous ulcers. Br J Dermatol. 1983;109(1):77-83.

28. Moberg S, Hoffman L, Grennert ML, Holst A. A randomized trial of cadexomer iodine in decubitus ulcers. J Am Geriatr Soc. 1983;31(8):462-5.

29. Lipsky BA, Hoey C. Topical antimicrobial therapy for treating chronic wounds. Clin Infect Dis. 2009;49(10):1541-9.

30. Draelos ZD, Rizer RL, Trookman NS. A comparison of postprocedural wound care treatments: do antibiotic-based ointments improve outcomes? J Am Acad Dermatol. 2011;64(3 Suppl):S23-9.

31. Taylor SC, Averyhart AN, Heath CR. Postprocedural wound-healing efficacy following removal of dermatosis papulosa nigra lesions in an African American population: a comparison of a skin protectant ointment and a topical antibiotic. J Am Acad Dermatol. 2011;64(3 Suppl):S30-5.

32. Langford JH, Artemi P, Benrimoj SI. Topical antimicrobial prophylaxis in minor wounds. Ann Pharmacother. 1997;31(5):559-63.

33. Maddox JS, Ware JC, Dillon HC Jr. The natural history of streptococcal skin infection: prevention with topical antibiotics. J Am Acad Dermatol. 1985;13(2 Pt 1):207-12.

34. Rogers HD, Desciak EB, Marcus RP, Wang S, MacKay-Wiggan J, Eliezri YD. Prospective study of wound infections in Mohs micrographic surgery using clean surgical technique in the absence of prophylactic antibiotics. J Am Acad Dermatol. 2010;63(5):842-51.

35. Levender MM, Davis SA, Kwatra SG, Williford PM, Feldman SR. Use of topical antibiotics as prophylaxis in clean dermatologic procedures. J Am Acad Dermatol. 2012;66(3):445-51.

36. Mulder G, Jones R, Cederholm-Williams S, Cherry G, Ryan T. Fibrin cuff lysis in chronic venous ulcers treated with a hydrocolloid dressing. Int J Dermatol. 1993;32(4):304-6.
37. Prete PE. Growth effects of Phaenicia sericata larval extracts on fibroblasts: mechanism for wound healing by maggot therapy. Life Sci. 1997;60(8):505-10.

38. Thomas S, Andrews A, Jones M, Church J. Maggots are useful in treating infected or necrotic wounds. BMJ. 1999;318(7186):807-8.

39. Ke Q, Costa M. Hypoxia-inducible factor-1 (HIF-1). Mol Pharmacol. 2006;70(5):1469-80.

40. Jones V, Grey JE, Harding KG. Wound dressings. BMJ. 2006;332(7544):777-80.

41. Barnett SE, Varley SJ. The effects of calcium alginate on wound healing. Ann R Coll Surg Engl. 1987;69(4):153-5.

42. Cullen B, Smith R, McCulloch E, Silcock D, Morrison L. Mechanism of action of PROMOGRAN, a protease modulating matrix, for the treatment of diabetic foot ulcers. Wound Repair Regen. 2002;10(1):16-25.

43. Beele H, Meuleneire F, Nahuys M, Percival SL. A prospective randomised open label study to evaluate the potential of a new silver alginate/carboxymethylcellulose antimicrobial wound dressing to promote wound healing. Int Wound J. 2010;7(4):262-70.

44. Percival SL, Bowler P, Woods EJ. Assessing the effect of an antimicrobial wound dressing on biofilms. Wound Repair Regen. 2008;16(1):52-7.

45. Dziewulski $P$, et al. Acute management of facial burns. In: Jeschke MG, Kamolz L-P, Sjöberg F, Wolf SE, editors. Handbook of burns vol. 1: acute burn care, 1st edn. New York: Springer; 2011. pp. 291-302.

46. Marston WA, Hanft J, Norwood P, Pollak R. The efficacy and safety of Dermagraft in improving the healing of chronic diabetic foot ulcers: results of a prospective randomized trial. Diabetes Care. 2003;26(6):1701-5.

47. Hanft JR, Surprenant MS. Healing of chronic foot ulcers in diabetic patients treated with a human fibroblast-derived dermis. J Foot Ankle Surg. 2002;41(5):291-9.

48. Newton DJ, Khan F, Belch JJ, Mitchell MR, Leese GP. Blood flow changes in diabetic foot ulcers treated with dermal replacement therapy. J Foot Ankle Surg. 2002;41(4):233-7.

49. Langer A, Rogowski W. Systematic review of economic evaluations of human cell-derived wound care products for the treatment of venous 
leg and diabetic foot ulcers. BMC Health Serv Res. 2009;9:115.

50. Driver VR, Lavery LA, Reyzelman AM, et al. A clinical trial of Integra Template for diabetic foot ulcer treatment. Wound Repair Regen. 2015;23(6):891-900.

51. Streubel PN, Stinner DJ, Obremskey WT. Use of negative-pressure wound therapy in orthopaedic trauma. J Am Acad Orthop Surg. 2012;20(9):564-74.

52. Venturi ML, Attinger CE, Mesbahi AN, Hess CL, Graw KS. Mechanisms and clinical applications of the vacuum-assisted closure (VAC) device: a review. Am J Clin Dermatol. 2005;6(3):185-94.

53. Smiell JM, Wieman TJ, Steed DL, Perry BH, Sampson AR, Schwab BH. Efficacy and safety of becaplermin (recombinant human platelet-derived growth factor-BB) in patients with nonhealing, lower extremity diabetic ulcers: a combined analysis of four randomized studies. Wound Repair Regen. 1999;7(5):335-46.

54. Barrientos S, Stojadinovic O, Golinko MS, Brem H, Tomic-Canic M. Growth factors and cytokines in wound healing. Wound Repair Regen. 2008;16(5):585-601.

55. Emmerson E, Campbell L, Davies FC, et al. Insulin-like growth factor-1 promotes wound healing in estrogen-deprived mice: new insights into cutaneous IGF-1R/ERalpha cross talk. J Invest Dermatol. 2012;132(12):2838-48.

56. Lima MH, Caricilli AM, de Abreu LL, et al. Topical insulin accelerates wound healing in diabetes by enhancing the AKT and ERK pathways: a double-blind placebo-controlled clinical trial. PLoS One. 2012;7(5):e36974.

57. Wu L, Xia YP, Roth SI, Gruskin E, Mustoe TA. Transforming growth factor-beta1 fails to stimulate wound healing and impairs its signal transduction in an aged ischemic ulcer model: importance of oxygen and age. Am J Pathol. 1999;154(1):301-9.

58. Wu SC, Marston W, Armstrong DG. Wound care: the role of advanced wound-healing technologies. J Am Podiatr Med Assoc. 2010;100(5):385-94.

59. Kranke P, Bennett M, Roeckl-Wiedmann I, Debus S. Hyperbaric oxygen therapy for chronic wounds. Cochrane Database Syst Rev. 2004;(2):CD004123.

60. Fonder MA, Lazarus GS, Cowan DA, Aronson-Cook B, Kohli AR, Mamelak AJ. Treating the chronic wound: a practical approach to the care of nonhealing wounds and wound care dressings. J Am Acad Dermatol. 2008;58(2):185-206.
61. Londahl M, Katzman P, Nilsson A, Hammarlund C. Hyperbaric oxygen therapy facilitates healing of chronic foot ulcers in patients with diabetes. Diabetes Care. 2010;33(5):998-1003.

62. O'Reilly D, Linden R, Fedorko L, et al. A prospective, double-blind, randomized, controlled clinical trial comparing standard wound care with adjunctive hyperbaric oxygen therapy (HBOT) to standard wound care only for the treatment of chronic, non-healing ulcers of the lower limb in patients with diabetes mellitus: a study protocol. Trials. 2011;12:69.

63. Han G, Nguyen LN, Macherla C, et al. Nitric oxide-releasing nanoparticles accelerate wound healing by promoting fibroblast migration and collagen deposition. Am J Pathol. 2012;180(4):1465-73.

64. Mowbray M, Tan X, Wheatley PS, Rossi AG, Morris RE, Weller RB. Topically applied nitric oxide induces T-lymphocyte infiltration in human skin, but minimal inflammation. J Invest Dermatol. 2008;128(2):352-60.

65. Lo DD, Zimmermann AS, Nauta A, Longaker MT, Lorenz HP. Scarless fetal skin wound healing update. Birth Defects Res C Embryo Today. 2012;96(3):237-47.

66. Larson BJ, Longaker MT, Lorenz HP. Scarless fetal wound healing: a basic science review. Plast Reconstr Surg. 2010;126(4):1172-80.

67. Wilgus TA. Regenerative healing in fetal skin: a review of the literature. Ostomy Wound Manage. 2007;53(6):16-31 (quiz 2-3).

68. Seifert AW, Kiama SG, Seifert MG, Goheen JR, Palmer TM, Maden M. Skin shedding and tissue regeneration in African spiny mice (Acomys). Nature. 2012;489(7417):561-5.

69. Degen KE, Gourdie RG. Embryonic wound healing: a primer for engineering novel therapies for tissue repair. Birth Defects Res C Embryo Today. 2012;96(3):258-70.

70. Badiavas EV, Falanga V. Treatment of chronic wounds with bone marrow-derived cells. Arch Dermatol. 2003;139(4):510-6.

71. McFarlin $\mathrm{K}$, Gao $\mathrm{X}$, Liu YB, et al. Bone marrow-derived mesenchymal stromal cells accelerate wound healing in the rat. Wound Repair Regen. 2006;14(4):471-8.

72. Jackson WM, Nesti LJ, Tuan RS. Mesenchymal stem cell therapy for attenuation of scar formation during wound healing. Stem Cell Res Ther. 2012;3(3):20. 